\title{
Fel kropp-berättelsen: vad är fel med den?
}

Af Ulrica Engdahl

Vad är fel med att vara i fel kropp? Vilka àtgärder är att föredra och på vilka grunder? Politiska och teoretiska tolkningar av fel kropp-berättelser både möjliggör och begränsar transpersoners förmaiga till självuttryck och erkännande.

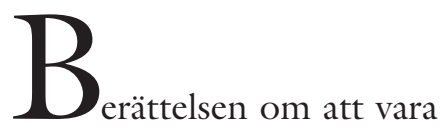
i fel kropp är vanlig som beskrivning av transkönade ${ }^{1}$ erfarenheter, särskilt förekommande i transbiografiska skildringar och medicinska kontexter. Berättelsen är kritiserad för att innebära en anpassning till medikaliserande, essentialiserande och begränsande normer. Jag kommer i denna artikel undersöka berättelsen ur ett transteoretiskt och kroppsfenomenologiskt perspektiv. Jag använder två olika transbiografiska citat med olika perspektiv på fel kropp-berättelsen som utgångspunkt för analysen. Citaten är valda mot bakgrund av att de representerar olika perspektiv på fel kropp-berättelsen.

Min teoretiska bakgrund är feministisk etik med teoretiska utgångspunkter i emancipatorisk-, queerfeministisk- och transteori. Med emancipatorisk teori menar jag teori som är situerad i konkreta och partikulära situationer av makt och förtryck där teorin syftar till att blottlägga bakomliggande strukturer och motverka dessa. Teoriutvecklingen orienteras därmed utifrån speci- 
fika politisk-praktiska intentioner, vilket bland annat innebär en politisk varsamhet inför semantiska och teoretiska konsekvenser och implikationer. Min icke-transkönade identitet gör den transpolitiska och personliga förankringen betydelsefull. Min intention är att använda det jag kallar lyssnandets metodologi som utgår från ett lyssnande ${ }^{2}$ till andras berättelser: "[...] rational reflection on justice begins in a hearing, in heeding a call" (Young 1990: 5). Lyssnandet utgår från andras kontextuella annanhet och erkännande av andras subjektskap, i motsats till blickens påträngande, objektifierande och isolerande konsekvens. Jag ämnar på så vis ersätta min brist på epistemiskt privilegium med epistemiskt tolkningsansvar.

“Alltihop startade en kväll när jag precis var på väg att gå och lägga mig. Jag gick från hallen till vardagsrummet för att släcka lampan och kastade en blick i fönstret i balkongdörren, den hade fönster nästan hela vägen ner så jag kunde se en spegelbild av hela mig, utan kläder. Och jag blev på något sätt förvånad över det jag fick se. Min första tanke var mest en känsla att något var fel, tätt följd av tanken att det var konstigt att jag kände så, eftersom jag såg ut som jag borde förvänta mig. Men jag blev stående där och funderade. För den som eventuellt gick förbi på gatan måste det ha sett intressant ut, en spritt språngande näck människa som står och ser ut att glo ut i mörkret. Och medan jag stod där så började jag långsamt inse att det jag egentligen hade förväntat mig var en kropp utan höfter som buktar ut, utan bröst, utan rundade former alls. Den enkla urtypen för en manskropp som man ritar den som barn. Jag blev egentligen aldrig rädd, det kändes mer som att kanske kunna få början en[sic] förklaring. En förklaring på varför jag alltid känt mig annorlunda, mer annorlunda än andra" (Romson 2009).

"I am a human being who is neither in a wrong body nor trapped in a wrong body but a human being who is expressing her beingness in one of the various forms of the human body. I am not in a wrong body. I am in this body just like how you are in your body. I am not trapped by my body. I am trapped by your beliefs. And I want to reclaim this body from those who want it to breathe and be fed by their dogmas" (Rogando Sassot, Sass 2010).

De båda citaten visar på olika erfarenheter av transkroppen. Det första citatet (citat 1) uttrycker en levd erfarenhet av att den egna kroppen är fel i relation till en självidentifierad könsidentitet, kroppen överensstämmer inte med de egna förväntningarna på utseende och uttryck. Det andra citatet (citat 2) uttrycker en levd erfarenhet av att vara transperson i en kropp som känns bekväm som den är. Istället uttrycks en känsla av att vara fångad av andras tolkningar och en önskan om att återta kroppen från dessa. Den levda erfarenheten av att vara transkönad är varierad. Trots det är den vanligast representerade berättelsen den om 'fel kropp'. De båda citaten visar på olika tolkningar av vad föreställningen om att vara $i$ fel kropp kan innebära.

\section{DE OLIKA BERÄTTELSERNA}

Det första citatet beskriver en persons upptäckt av den egna kroppen som felaktig i relation till de egna förväntningarna på den. Upptäckten sker genom en spegelbild i ett fönster, blicken på den egna kroppen var vid tillfället oväntad vilken kan ha varit avgörande för upptäckten. Personen beskriver en känsla av förvåning över utseendet på kroppen, följt av en känsla av att något är fel, samt funderingen över att det är konstigt att han känner så eftersom han ser ut som han borde förvänta sig. Detta föranleder insikten att det är just där problemet ligger - han hade förväntat sig en annan kropp: “... en kropp utan höfter som buktar ut, utan bröst, utan rundade former alls. Den enkla urtypen för en manskropp som 
man ritar den som barn." Citatet avslutas med beskrivningen av att få en förklaring på en känsla av annorlundaskap som personen alltid känt.

I citatet framkommer: 1) känsla av förvåning inför den egna spegelbilden, 2) tanken att förvåningen är konstig, 3) insikten om en förväntan på en kropp med ett annorlunda könskodat utseende, 4) beskrivning av förväntan på ett manligt könskodat utseende och 5) en känsla av möjlig förklaring till erfarenheten av annorlundaskap.

Jag tolkar detta som en fel kropp-berättelse även om fel kropp inte nämns. Berättelsen beskriver förvåning inför den egna kroppen och en förväntan på ett annat utseende. Citatet uttrycker en diskrepans mellan kroppen och en inre känsla av och förväntan på ett utseende som är manligt kodat. Det är intressant att notera att diskrepansen upptäcks genom en spegelbild; det är snarare en diskrepans mellan utseende och en inre förväntan än en inre känsla av obekvämlighet som beskrivs.

En betydelsefull aspekt i citatet är förvåningen inför synen av den egna kroppen och upptäckten av de egna förväntningarna på dess utseende som manligt könskodat, vilket motsägs av den vid tidpunkten kvinnligt kodade kroppen. Här finns flera laddade föreställningar om manligt, kvinnligt och motsatta könskoder med betydelse för erfarenheten av fel kropp.

I det andra citatet beskriver personen sig själv som människa, vilket jag tolkar som en betoning av människoskap framför det könade uttrycket av en könsidentitet. Hon påtalar vidare att hon inte är i fel kropp eller är fångad i fel kropp, utan i en (normal) kropp (som alla andra). Hon skriver att hon är en människa som uttrycker sitt vara på ett av flera möjliga sätt att vara människa på. Här betonas mänsklig variation av kropp och uttryck. Därefter påpekas likheten i hur vi är könade i våra kroppar. Skillnaden beskriver hon som att hon är fångad av andras tolkningar av kön och kropp, särskilt hennes (och andra transpersoners) kropp. Citatet avslutas med ett uttryck av en önskan att återta den egna kroppen från dem som "vill att den ska andas och födas av deras tolkningar" (min översättning).

Citatet uttrycker: 1) ett varierat sätt att vara (trans)könad i sin kropp, 2) ett nekande av fel kropp-erfarenhet, 3) en känsla av att vara bekväm i kroppen som den är, 4) att kroppen är fångad av andras tolkningar av den, samt 5 ) en vilja att återta den från andras tolkningar. Jag tolkar citatet så att det uttrycker en betoning på människoskap framför könstillhörighet och olika sätt att vara i kroppen, samtidigt som alla delar en erfarenhet av att vara i sin kropp samt att andras övertygelser făngar transpersoner och deras tillgång till sina egna kroppar genom att begränsa deras möjlighet till varierade uttryck. Återtagandet av den kroppsliga erfarenheten av att vara bekväm med sin kropp (oavsett könskodat uttryck och materialitet) handlar om att erkännas utan förväntan på förändring och anpassning.

Detta citat skiljer sig på flera sätt från det förra med avseende på fel kropp-temat. Här poängteras att kroppen erfars på samma sätt som för andra, att hon inte är fångad i sin kropp, däremot uttrycks en känsla av att vara fångad av andras tolkningar av den. Jag tolkar det så att dessa tolkningar konstruerar förutsättningar för kroppars förmåga till självuttryck. Tolkningarna får därigenom konkreta konsekvenser för transpersoners möjlighet att vara i och uttrycka sig med kroppen och bli sedda, tolkade och bemötta enligt en subjektivt självidentifierad identitet.

\section{DISTINKTIONEN MELLAN KÖN OCH GENUS}

Citat 1 uttrycker ett perspektiv som vilar på föreställningen om en eftersträvansvärd överensstämmelse mellan kropp och könsidentitet och att kunna passera i den självidentifierade könsidentiteten. Enligt detta perspektiv är kroppslig förändring nödvändig för att känna sig bekväm med kroppen, 
för möjligheten till självuttryck och för att bli bemött av andra i enlighet med detta. Citat 2 uttrycker ett perspektiv som medger bekvämlighet med kroppen utan anpassning. Kroppen erfars inte som fel, utan felet placeras i andra människors tolkningar av den. Här betonas variation av kroppsliga och könade sätt att vara. En teoretisk och politisk spänning kan sägas föreligga och härröra från den paradoxala politiska konsekvensen som innebär att uttryck av transerfarenheter kan tyckas underminera könsbinära normer och samtidigt befästa den könsbinära modellen och könens betydelse som begripliga kategorier (Cromwell 1999: 41).

Distinktionen mellan kön och genus möjliggör ett isärhållande av kön som kropp (biologi) och genus som könsuttryck och könsidentitet (socialt och kulturellt). Det innebär att det är möjligt att tala om könsnormer som oberoende av biologisk förankring genom att till exempel påvisa variation i tid och rum (Kulick 1987: 11) och för att kunna tala om skillnader mellan män och kvinnor utan att för den skull åsyfta biologiska och determinerande skillnader (Gemzöe 2005). Samtidigt befäster distinktionen åtskillnaden mellan antaganden om det givna (verklighet) och det föränderliga (konstruktion), vilket i en transkontext förmedlar en föreställning om genitalier som könslig verklighet och könsuttryck som könslig maskerad (Se Bettchner 2009). Judith Butler kritiserar i Gender Trouble (1990) distinktionen mellan kön och genus genom att påpeka att både kön och genus, liksom distinktionen i sig, är en social konstruktion och att det inte finns någon könsidentitet bakom könsuttryck:

There is no gender identity behind the expressions of gender; that identity is performatively constituted by the very "expressions" that are said to be its results. (Butler 1990: $25)$.

Samtidigt förefaller kön- och genusdistink- tionen vara en förutsättning för talet om transkönade erfarenheter av att vara i fel kropp. Uttrycket 'fel kropp' förutsätter att det går att särskilja kropp från det subjekt som erfar och beskriver kroppen som fel. Utifrån ett performativt perspektiv existerar inte subjektet isolerat från varken kropp eller omgivning, utan konstitueras i samspel med dessa. Det innebär att subjektet konstitueras av kroppens uttryck och omgivningens tolkande blickar, vilket skulle kunna förklara den upplevda diskrepansen mellan kropp och uttryck samt känslan av att vara i fel kropp. Detta innebär inte att fel kropp-erfarenheten kan förklaras enbart som beroende av omgivningens tolkning och som kroppens brist på (materiella) förutsättningar för könskodade utryck. Inte heller kan den enbart förklaras som en essentiell inre verklighet isolerad från materia och omgivning. Det är snarare så att subjektets erfarenhet, dets möjlighet till uttryck samt omgivningens tolkning samverkar till att konstituera en känsla av att vara i fel kropp.

\section{DEN KROPPSLIGA ERFARENHETEN}

Ett sätt att förstå fel kropp-berättelser är inom ramen för begreppet 'den levda kroppen'; “The lived body is a unified idea of a physical body acting and experiencing in a specific sociocultural context; it is body-insituation." (Young 2005: 16). Betoningen av kroppen-i-situation är fruktbar för förståelsen av fel kropp-berättelsen, då det erbjuder en möjlig situationsbestämd tolkning av den. På så vis blir det möjligt att förstå den som beroende av specifika situationer snarare än att vara en essentiell och isolerad erfarenhet. Den levda kroppen innebär i en existentiell mening att kroppen förstås och erfars samtidigt genom dess materiella förutsättningar och genom dess relation till en omgivning samt specifika och eventuellt tillfälliga situationer. Omgivningens blickar och strävan efter att tolka kroppen genom att normalisera den (i enlighet 
med den könsbinära tolkningsramen) medverkar till erfarenhet av att kroppen är fel, då det inte finns någon annan tillgänglig tolkningsmöjlighet av den. Detta innebär inte att det inte finns en subjektiv erfarenhet av den egna kroppen som 'fel', bara att dessa konstitueras i relation till en omgivning och i samspel med den. Medicinska tolkningar av transkönade kroppar innebär att det redan finns en förklaring och en berättelse att relatera den egna erfarenheten till. En berättelse som klär känslor och erfarenheter i redan tillgängliga, men eventuellt värdeladdade ord.

Ett annat sätt att tolka transkönade kroppar är genom Gayle Salamons begrepp 'a felt sense of a body' (kroppserfarenhet). Salamon beskriver 'kroppserfarenhet' som en kombination av den fenomenologiska termen 'proprioception', det psykoanalytiska 'bodily ego' och en transteoretisk hänvisning till 'realness' (Salamon 2010: 2). Salamon understryker kulturella tolkningars betydelse för den mening som en specifik kroppslig känsla har, samtidigt som hon klargör att det inte förminskar den subjektivt upplevda känslan av kroppslig mening (ibid: 3 ). Kroppar beskrivs, med hänvisning till Merlau-Ponty, som konstituerade både genom ett själv och en materiell omgivning, samt att kroppar materialiseras i relation med andra (ibid: 5). Med hjälp av Freuds begrepp 'bodily ego' (kropps-jag) blir det möjligt att förklara hur kroppserfarenheten inte alltid överensstämmer med den fysiskt tillgängliga kroppen så som den uppfattas av andra:

To understand embodiment as necessarily routed through a bodily ego is not to contend that body and ego are coterminous or self same, but to assert that projections of various kinds are required in the construction of both the ego and the body, that the ego is itself a projection, and that difference, distance, and otherness are at the heart of the ego and the body. (Salamon 2010: 14)
Detsamma gäller materialitet och diskursivitet (ibid.: 40). Kroppslighet kan förstås genom en sammanflätning mellan subjektivitet, materialitet och diskursivitet. Berättelser om fel kropp kan med hjälp av Salamons terminologi tolkas som en kropps-erfarenhet, där en subjektivt upplevd kroppslig mening (ett kropps-jag) samverkar med kulturella tolkningar av kroppen och där den subjektiva (kropps-jaget) och den kulturella tolkningen (blickar på kroppen) inte överensstämmer. Diskrepansen kan erfaras som att kroppen är fel i relation till kroppsjaget (se citat 1). Det är också möjligt att erfara eller tolka det så att den subjektiva kroppserfarenheten skiljer sig åt från de kulturella tolkningarna av den utan att det upplevs som att felet ligger hos den egna kroppen eller resulterar i en önskan om förändring av den. Genom den fenomenologiska tolkningen av kroppserfarenheten som subjektivt, materiellt och diskursivt konstituerad ges utrymme för de båda (i citaten förekommande) kroppserfarenheterna inom samma tolkningsparadigm, utan att någon med nödvändighet ges tolkningsföreträde.

\section{EN LEVD VERKLIGHET?}

Föreställningar om en verklighet och om autentiska identiteter är epistemologiskt, etiskt och politiskt problematiska i det att de bidrar till en falsk och determinerande föreställning om människors vara. Samtidigt innebär ett förnekande av en personlig erfarenhet av levd verklighet en kränkning och ett misserkännande. Den levda erfarenheten av en 'verklig' identitet bör istället förstås som en subjektiv meningsbärande erfarenhet, sammanflätad med materiella förutsättningar och diskursiva tolkningar av den. Förväntningarna på den egna kroppens utseende som beskrivs i citat 1 är resultatet av kropps-jagets subjektiva erfarenhet, konstituerad tillsammans med kroppslig materia och diskursiva tolkningar av den. Det betyder inte att den är mindre på- 
taglig, sann eller verklig (som erfarenhet), bara att den är verklig i en reflexiv mening genom dess konkreta konsekvenser för personen ifråga. Den materiella oförmågan till självuttryck kan inte bortförklaras med diskursivitet och den kan enbart åtgärdas genom ett möjliggörande av självuttryck som kan ske på flera sätt; genom kirurgisk, hormonell, juridisk eller social korrigering tillsammans med erkännande av kropps-jagets identitetserfarenhet. Jamison Green, ${ }^{3}$ konsult och utbildare i transfrågor, uttrycker i citatet som följer denna samverkan:

One thing is certain: taking testosterone will not make a social female into a social male. It will change some sex-differentiated characteristics that are interpreted socially as male, but it won't make a man of anyone. Being a man is more than looking like one. It also requires being comfortable in the body of a man, and that is something testosterone can certainly assist, but only if it is within the individual's comfort zone (Green 2004: 94).

I citat 2 tolkas den materiella oförmågan och begränsningen av självuttrycket som grundad i omgivningens tolkningar. Citatet uttrycker ett annat sätt att vara transkönad på än det som fel kropp-berättelsen anger, ett sätt som inte är sanktionerat av varken juridisk eller medicinsk praxis. Erkännande av självidentifierad könsidentitet är därmed villkorad av både en fel kropps-diskurs, kroppslig förändring samt en linjär könsbinaritet. Det är inte möjligt att erhålla juridiskt erkännande för en könsvarierad identitet eller alternativt könskodad tredje könskategori. Den transkönade kroppserfarenheten som inbegriper en känsla av att vara $\mathrm{i}$ fel kropp, att önska korrigering och att passera i den självidentifierade könsidentiteten kan göras begriplig eftersom den befinner sig inom ramen för den binära könsmodellen. Citat 2 uttrycker istället erfarenheten av att vara bekväm i en 'normal' men annorlunda kroppserfarenhet och placerar orsaken till diskrepansen mellan kropp(sut- tryck) och kropps-jag hos de diskursiva tolkningarna. Personen i citatet vill återta sin kropp från dessa tolkningar. Det innebär att förändringen placeras utanför det egna subjektet och den egna kroppen. Omgivningens anpassning till en konkret levd verklighet av kropps- och identitetserfarenheter efterfrågas och sker genom en samverkan med olika andra subjekt, materialiteter och diskursiviteter.

\section{(O)SYNLIGHET}

En konkret konsekvens av att kropps-jaget och de diskursiva tolkningarna av den inte överensstämmer är osynlighet. Samtidigt kan det sägas vara så att osynligheten konstruerar den subjektiva identitetserfarenheten som en erfarenhet av att vara i fel kropp. Erfarenheten att inte vara synlig för andra enligt den självidentifierade identiteten innebär att en är synlig som någon (könsmässigt) annan. Berättelsen om fel kropp hör därmed samman med levd erfarenhet av osynlighet.

I am real; I am an authentic and reliable man. I am also a transsexual man. I am a man who lived for 40 years in the body of a woman, so I have had access to knowledge that most men do not have. Invisibility has been a major issue in my life. Throughout my childhood and young adulthood I - my identity was, for the most part, invisible. I was always defined by others, categorized either by my lack of femininity, or by my female body, or by the disquieting combination of both (Green 2006: 506).

Här framkommer en subjektiv identitetserfarenhet (ett kropps-jag) som erfars vara osynlig, genom andras diskursiva tolkning och kategorisering, vilande på förekomsten av en (synlig) kvinnligt kodad kropp som inte medger ett subjektivt manligt kodat självuttryck. Jag tolkar citatet som ett uttryck för ett fel kropp-tema i och med dess hänvisning till 1) ett kropps-jag som erfars 
vara osynligt och 2) en kvinnligt kodad kropp som förklaring till osynligheten samt 3) en känsla av att vara utelämnad till andras tolkning av den egna kroppen (och därmed implicit av kropps-jaget). Jag finner här likheter med citat 1 , i och med erfarenheten av ett osynligt kropps-jag, och citat 2 angående den återgivna erfarenheten av att vara făngad av andras tolkningar av den egna kroppen.

Referensen till att vara verklig och äkta indikerar en essentiell och determinerande förståelse av identitet. Betoningen på 'verklig' och 'äkta' är ett sätt att (i specifika situationer) signalera den subjektiva identitetserfarenheten som trovärdig och i kontrast till felaktigt könskodade identitetstillskrivningar. Termerna 'verklig' och 'äkta' bör här förstås i kontrast till omgivningars förståelse av kön som en biologisk fakticitet, vilket innebär att könsvarierade identiteter tolkas som en slags maskerad som bara är 'på låtsas'. Green påpekar vidare: “I am also a transsexual man.” Det som betonas här är möjligheten att vara en man som både är verklig (som man) och transsexuell, utan att göra avkall på äktheten hos kropps-jaget. Föreställningen om äkthet visar på en känsla av essens som upplevs som ofrånkomlig.

Synlighet utgör en central dimension i ett transpolitiskt sammanhang där det är en viktig strategi för transinklusiv rättvisa. Möjlighet till deltagande är villkorat genom synlighet och igenkännande. ${ }^{4}$ Greens hänvisning till den självidentifierade manliga könsidentiteten som äkta uttrycker ett motstånd mot förgivettagna och biologistiska föreställningar om möjliga könskategorier.

Walking down the street in San Francisco or in New York City, Tokyo, Sydney, Paris or Rome, no one takes any special interest in me. I am just another man, invisible, no one special. I remember what it was first like to feel that anonymity as testosterone gradually obliterated the androgyny that for most of my life made others uncomfortable in my pres- ence. It was a great relief to be able to shake off layers of defensive behaviours developed to communicate my humanity from inside my uncategorizability. It was a joy to be assumed human for a change; instead of gawked at, scrutinized for signs of any gender. Now, whenever I stand up in front of a college class or a corporate training session, or make any public statement in support of transgendered or transsexual people, I am scrutinized for signs of my previous sex, even though my gender is perfectly obvious, reinforced by my male appearance (Green 2004: 182).

I citatet betonar Green anonymitetskänslan i passerandet, känslan av att vara en i mängden, att smälta in och vara delaktig. Anonymitets-osynligheten beskrivs som efterlängtad och positiv, det förefaller vara en lättnad att inte utmärka sig. Det är en osynlighet som är nära besläktad med normalitet, genom att det normala tas för givet, inte ifrågasätts och inte heller märks.

\section{SJÄLVUTTRYCK, ERKÄNNANDE OCH ATT PASSERA}

Kroppsliga förutsättningar för könskodat självuttryck, det vill säga de möjligheter kroppen har genom dess materialitet (anatomi, utseende, och rörelsemönster) att uttrycka en specifikt könskodad identitet, är av central betydelse för transpersoners möjlighet till att bli sedda i enlighet med den självidentifierade identiteten. Kroppens förutsättningar för detta kan ändras genom kirurgi, hormonterapi, socialt erkännande och/eller genom förändring av tillgängliga föreställningar. Det senare kommer till stånd bland annat genom synlighet, på så vis är det möjligt att förändra könsbinära normer och diskursiva tolkningsramer. Synliga presentationer och berättelser påverkar den imaginära föreställningen som finns tillgänglig som tolkningsram.

Levda kroppserfarenheter av att vara i fel kropp bör inte ignoreras eller ifrågasättas politiskt, då det innebär ett misserkännan- 
de. På ett epistemologiskt plan kan vi ifrågasätta berättelsen om och erfarenheten av den felaktiga kroppen. Både dess antaganden och konsekvenser kan analyseras som teoretiskt likaväl som politiskt problematiska. I en mening kan den förstås som en underkastelse under sociala och medicinska normer, å andra sidan kan det också förstås som ett tillgängligt sätt att klä erfarenheter i ord. Transpersoner som genomgår könskorrigering och som väljer att passera är agerande subjekt som konstruerar (på samma sätt som alla, fast på ett eventuellt mer medvetet sätt än andra) sin könsidentitet.

To find that you are fundamentally unintelligible (indeed, that the laws of culture and language find you to be an impossibility) is to find that you have not yet achieved access to the human, to find yourself speaking only and always as if you were human, but with the sense that you are not, to find that your language is hollow, that no recognition is forthcoming because the norms by which recognition takes place are not in your favour (Butler 2004: 30) (Butlers kursivering).

Butler beskriver obegripligheten som att vara utesluten från ett människoskap. Språk, benämning och tilltal uttrycker normer, varför erkännande omöjliggörs när språkets uttrycksmöjligheter begränsas. Jag tolkar det som att språket begränsar kroppar, subjekt och uttryck. Ömsesidigt erkännande som igenkännande och bekräftelse av varierade kroppserfarenheter och könsuttryck är därmed villkorat diskursiva tillgängliga tolkningar.

Att passera kan tolkas som att inkluderas i en sfär av begriplighet. Amanda Brihed talar i en debattartikel om den transkönade erfarenheten som präglad av en längtan efter delaktighet, orsakad av medicinska tolkningars begränsning av transpersoners möjlighet till detsamma (Brihed 2011). Jag tolkar Greens citat om anonymitetskänslan och beskrivningen av glädjen i att smälta in som en beskrivning av delaktighet. "It was a joy to be assumed human for a change" (Green 2004: 182).

Passerandeidealet är ifrågasatt av bland andra Sandy Stone som menar att det befäster osynligheten av transerfarenheter i och med att det fokuserar på en könsbinär presentation. Här återfinns en politisk spänning mellan ett personligt passerandeideal (längtan efter delaktighet) och ett personligt-politiskt öppenhetsideal. Det finns ytterligare en spänning mellan passerandeidealet och ett könsvariationsideal. Spänningen berör dels ett politiskt ideal om öppenhet som ett sätt att främja synlighet, dels idealet om en mer flexibel könsförståelse där könsvariation och fler könskategorier är möjlig. Båda dessa ideal försvåras av osynlighet. Sandy Stone förespråkar "posttranssexualism", vilket innebär ett synliggörande av mångfalden av transerfarenheter och ett erkännande av den transsexuella erfarenheten i självidentifierade könsidentiteter (Stone 2006). Jason Cromwell inför en distinktion mellan att vara sedd och att bli (av)läst, där att bli (av)läst relateras till ett avslöjande baserad på en uppfattning om den biologiska och materiella kroppen som den verkliga identitetsmarkören.

Many transpeople feel they are passing, "doing drag," and living a lie when they attempt to live in their assigned sex; for them, doing so is a matter of disguise, masquerade, and pretense. Rather than passing, many FTMs and transmen feel they are being seen as their true selves in living, dressing and behaving as men. Being seen rather than being read is an important distinction. The latter implies an intent to deceive and falsehood; the former is a recognition that there is no deception and that observers see those whom they observe as they see themselves (Cromwell 1999: 39).

Cromwell föreslår en omvänd tolkning av passerandet som medger en betydelseförskjutning från tolkningen av verklighet som det biologiskt kroppsliga till att represen- 
teras av det könsuttryck som möjliggörs genom att vara sedd.

\section{AVSLUTANDE DISKUSSION}

Jag har argumenterat för att fel kropp-berättelser bör tolkas fenomenologiskt med hjälp av begreppen 'en levd kropp', 'kroppserfarenhet' och 'kropps-jag'. En sådan tolkning medger en konstituerande samverkan mellan subjektiva erfarenheter, materiella förutsättningar och diskursiva tolkningar. Tolkningen betonar den relationella och situationsbestämda aspekten, det vill säga hur vi blir till under varandras blickar och genom varandras lyssnande och tilltal.

Vidare har jag diskuterat fel kropps-berättelsen som beroende av distinktionen mellan kön och genus, samt hur Butlers invändning mot den ger en viktig nyckel till en nyanserad tolkning av denna. Genom Butlers påtalande av hur subjektet konstitueras av de uttryck som vanligen tolkas som emanerade från den, tillsammans med diskursiva tolkningar och tillgängliga språkbruk bryts distinktionen upp. Jag tolkar det som att diskursivitet, materialitet och osynlighet konstituerar kropps-jagets erfarenhet av att vara i fel kropp. Det öppnar för ett möjligt erkännande av kropps-jaget som verkligt i en reflexiv mening, det vill säga genom dess konkreta konsekvenser för personer, samtidigt som det innebär att den subjektiva verkligheten tolkas som en konstruktion. Tolkningen av den subjektiva verkligheten bör inte förstås som 'bara' konstruktion, konstruktionen bör snarare förstås som ett konstituerande av verkligheten. Jag menar att det inte existerar någon egentlig motsättning mellan verklighet och konstruktion, sociala konstruktioner är den verklighet vi har för handen. I en transkontext där könserfarenheter och uttryck ofta är osynliga, svårbegripliga eller obegripliga i en könsbinär tolkningsram, kan hänvisning till verklighet vara ett sätt att betona subjektets tolkningsföreträde av det egna livet, dess möjligheter och begräns- ningar. Att vara i fel kropp förstås därmed som en sub-jektiv verklighetstolkning.

Hur kan vi förstå fel kropp-berättelser? Jag menar att vi bör förstå dem som för det första ett uttryck för en levd erfarenhet, för det andra som ett uttryck för en medikaliserad förståelse, för det tredje som en strävan efter normalisering av kroppar och uttryck och för det fjärde som en längtan efter delaktighet. Det finns ingen tillgänglig tolkningsram för könsvariation varför varierade kroppsliga uttryck pressas in i en könsbinär modell för att framstå som igenkännbara och tolkningsbara (Halberstam 1998: 22, 27).

Jag menar att det som är fel med berättelsen om fel kropp är den könsbinära modellens tolkningsföreträde av kön, könad identitet, kropp och uttryck. Den begränsar personers möjlighet till självidentifierade könsuttryck och till att bli sedda och bemötta i enlighet med dem. Erfarenheten av att vara i fel kropp och att vara osynlig i och med de materiella förutsättningarna den tillgängliga kroppen erbjuder och genom de tolkningsmöjligheter som den könsbinära föreställningsvärlden tillhandahåller, innebär svårigheter för den personliga existensens erkännande och för deltagande i sociala, politiska och publika rum. Den mest verkningsfulla åtgärden för att komma till rätta med den kroppsliga diskrepansen och de exkluderingsmekanismer den föranleder är att ersätta den könsbinära modellen med en könsvarierad modell. I en könsvarierad modell betonas kön som ett flytande och varierat begrepp. Modellen erbjuder därmed fler könskategorier och fler möjligheter till könsuttryck. Det innebär att subjektiva erfarenheter, materiella förutsättningar och diskursiva tolkningar varieras, synliggörs och erkänns genom ömsesidigt lyssnande till levda erfarenheter av en konkret (trans)könad verklighet, både för de som uttrycker en känsla av att vara i fel kropp och de som varierar kroppsligt könade erfarenheter och uttryck. 


\section{Notes}

1. Jag använder transkönad som ett samlingsnamn för erfarenheter av olika slags könsvariation, vissa erfarenheter är mer specifika för särskilda slag av könsvariation, då benämner jag dem därefter.

2. I bildlig bemärkelse, här har jag enbart ägnat mig åt läsning av transbiografiska utsagor.

3. Jamison Green är transpolitisk aktivist, utbildare och konsult och har skrivit boken Becoming a Visible Man.

4. Se Judith Butlers diskussion om osynlighet, obegriplighet och det omöjliga människoskapet i Butler 2004, 17-39.

\section{LITTERATUR}

- Arver, Stefan; Dhejne Cecilia och Öberg, Katarina: Transsexualism (uppslagsord). Internetmedicin.se, http://www.internetmedicin.se/dyn_ main .asp?page $=3422(2011-05-30)$.

- Bettcher, Talia Mae (2009): Trans Identities and First-Person Authority, i: Laurie J. Shrage (red.): "You've Changed": Sex Reassignment and Personal Identity. Oxford University Press, Oxford, New York.

- Brihed, Amanda (2011): Manligheten sitter inte $i$ anatomin $\mathrm{SvD}, 1$ aug, lokaliserat 15 augusti, 201 1: http://www.svd.se/opinion/brannpunkt/manligheten-sitter-inte-i-anatomin_6360928.svd - Butler, Judith (1990): Gender Trouble: Feminism and the Subversion of Identity. Routledge, New York and London.

- Butler, Judith (2004): Undoing Gender. Routledge, New York and London.

- Cromwell, Jason (1999): Transmen and FTM:s: Identities, Bodies, Genders and Sexualities. University of Illinois Press, Urbana and Chicago

- Engdahl, Ulrica (2011): Att vara som/den 'en' är: en etisk diskussion om begreppen rättvisa, erkännande och identitet $i$ en trans*kontext. Linköping Studies in Art and Sciences Nr. 522, LiU Tryck, Linköping

· Gemzöe, Lena (2005): Feminism. Bilda förlag, Stockholm.

- Green, Jamison (2004): Becoming a Visible Man. Vanderbilt University Press, Nashville, Tennessee. - Green, Jamison (2006): Look! No, don't! The Visibility Dilemma for Transsexual Men, i: Stryker, Susan and Whittle, Stephen (ed.): The Transgender Studies Reader. Routledge Taylor \& Francis Group, New York and London.

- Halberstam, Judith (1998): Feminine Masculinity. Duke University Press, Durham and London.
· Hekman, Susan (ed.) (1999): Feminism, Identity and Difference. Frank Cass, London and Portland. - Kulick, Don (red.) (1987): Från kön till genus: kvinnligt och manligt $i$ ett kulturellt perspektiv. Carlssons Bokförlag, Stockholm.

- Rogando Sasot, Sass, tal 6 okt 2010, under en lektion om genus och sexualitet (the University of Philippines - Diliman) (hämtat från en facebooksida 4 maj 2011).

- Romson, Lukas, 2 September, 2011

www.lukas.romson.org/komma-ut-historia.htm. - Salamon, Gayle (2010): Assuming a Body: Transgender and Rhetorics of Materiality. Columbia University Press, New York, Chichester, West Sussex.

- Stone, Sandy (2006): The Empire Strikes Back: A Posttranssexual Manifesto, i: Stryker, Susan and Stephen Whittle (ed.): The Transgender Studies Reader. Routledge, New York, London.

- Young, Iris Marion (2005): On female body experience: throwing like a girl and other essays. Oxford University Press, New York

\section{SUMMARY}

The wrong-body-narrative - what's wrong with it?

The common story of being "trapped in the wrong body" has become pivotal of trans experiences and indicative of what it means to be transsexual, often found in autobiographical accounts as well as in medical contexts of gender reassignment practice. Queer theorists as well as trans theorists and activists have critiqued the wrong-body-narrative for its complicity with essentialist, reifying, dominant and oppressive gender binary norms. In this article I argue for a phenomenological approach to the wrong-body-narrative. This is done through a series of conceptual suggestions that works to reframe the phenomenon to encompass such critical perspectives while they simultaneously make room for a wider spectrum of epistemological, ethical and ontological dimensions of the very experiences that inhabit the wrong body narrative.

Ulrica Engdahl, FD

Tema Genus, Institutionen för Tema

Linköpings Universitet 